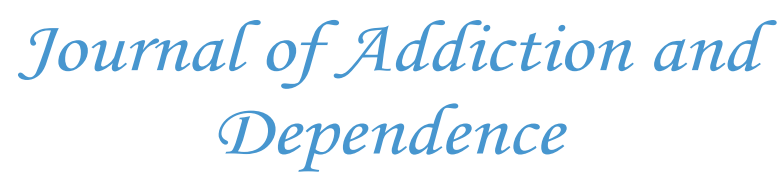

\title{
Cannabis Induced Psychosis Treatment: An Original Approach
}

\author{
Jamshid Ahmadi*
}

Substance Abuse Research Center, Shiraz University of Medical Sciences, Shiraz, Iran

*Corresponding author: Jamshid Ahmadi, MD, Professor of Psychiatry Founder and Director, Substance Abuse Research Center, Shiraz University of Medical Sciences, Shiraz, Iran, E-mail: Jamshid_Ahmadi@yahoo.com

\begin{abstract}
Background: Cannabis use disorders and induced disorders are common in the world. Objective: To discuss an emergency psychotic patient having diagnosis of cannabis induced psychosis with severe use disorder who responded successfully to Electro Convulsive Therapy (ECT).

Results: The patient improved after ECT administration.

Discussion: This study clarified that ECT could be life saving in this serious situation. Conclusion: ECT is a good choice in the treatment of cannabis induced psychosis and cannabis withdrawal symptoms.
\end{abstract}

Keywords: Cannabis; Psychosis; ECT
Received Date: March 19, 2016

Accepted Date: June 3, 2016

Published Date: June 7, 2016

Citation: Ahmadi, J. Cannabis Induced Psychosis Treatment: An Original Approach. (2016) J Addict Depend 2(2): 79- 80 .

DOI: $10.15436 / 2471-061 X-16-019$

\section{Introduction}

Since the rate of psychiatric disorders is raising thus health authorities and researchers pay more attention to the epidemiology, etiology, prevention and treatment of mental disorders ${ }^{[1-9]}$. Among psychiatric diseases, substance related disorders, especially cannabis and stimulant induced disorders have been considered as advancing problems. Currently cannabis and stimulant related psychiatric presentations to the outpatient and inpatient centers is a raising dilemma ${ }^{[10-16]}$.

In Iran, in the past time cannabis and methamphetamine were illegally smuggled in from other countries, but at present it they are prepared illegally in 'underground'. Cannabis has not only been illegally smuggled in from the east and the west countries, but also has been cultivated in 'underground'. Hashish potency is more than marijuana and is sometimes joined with psychosis. A single episode of abuse may cause hallucinations and paranoid persecutory delusions ${ }^{[10]}$.

\section{Case Presentation}

MH was a 21 years old single, unemployed with $1^{\text {st }}$ grade of high school education. He lived with his parents in Kazeroon city of Fars province in south of Iran. MH started drinking alcohol at age of 13 and smoking tobacco at age of 14. Because of heavy alcohol drinking he gradually developed aggressive behaviors, irritability, and impulsivity. He had several fighting with others that resulted to his imprisonment at age of 18 . He was in prison for 3 years and in this period he began smoking opium, cannabis and methamphetamine. After releasing from prison he started abusing alcohol, benzodiazepines, heroin, cannabis and methamphetamine. MH developed depressed mood, unhedonia, suicidal acts, paranoid delusion, impulsive behaviors and homicidal acts. Since one month prior to admission he increased smoking of heroin and hashish and then his symptoms were exaggerated.

He had not history of psychiatric disorders in his family. He was admitted in the dual diagnosis ward of Ebnesina hospital in the city of Shiraz in April, 2016. During comprehensive psychiatric interview and detailed examination, he had opioid and cannabis withdrawal symptoms, depressed mood, severe irritability, suicidal and homicidal acts, paranoid delusion and aggressive behavior. In physical and neurological examinations we could not find any significant abnormality. Laboratory tests including screening tests for viral markers (HIV, $\mathrm{HCV}$ and $\mathrm{HB} \mathrm{Ag}$ ) were normal. Urine drug screening tests were positive for THC, methadone and benzodi-

Copyrights: (C) 2016 Ahmadi, J. This is an Open access article distributed under the terms of Creative Commons Attribution 4.0 International License. 
azepine. According to comprehensive medical, psychiatric, and substance use history and DSM-5 criteria he was diagnosed as cannabis induced psychotic disorder

At the time of admission he was complaining of severe irritability, agitation, insomnia and opioid withdrawals. We administered olanzapine $30 \mathrm{mg}$ and chlorpromazine $500 \mathrm{mg}$ per day for the treatment of insomnia, and severe agitation. Patient received ibuprofen $1200 \mathrm{mg}$, clonidine $0.3 \mathrm{mg}$ and baclofen 75 $\mathrm{mg}$ per day for the management of opioid withdrawals.

In the $2^{\text {nd }}$ day of admission, due to the emergency condition of the patient and lack of response to the prescribed medication, we began double bilateral electroconvulsive therapy (ECT) i.e. 2 sessions of ECT in the same anesthesia phase. In the day of admission his cannabis withdrawal craving score and heroin withdrawal pain score were high.

With reference to the interview, close monitoring, and precise measurement ( 3 times a day) for cannabis and heroin withdrawal symptoms, $\mathrm{MH}$ experienced and reported a fast declining level of craving and pain after receiving the 3rdsession of double ECT. After one month of hospital admission and receiving 9 sessions of double ECT (overall 18 sessions of ECT), patient was discharged without any psychiatric or withdrawal symptoms.

\section{Discussion}

I should mention that in Iran the patients should be admitted to a facility as per law of the country ${ }^{[17]}$.

Our work indicates that ECT may be useful and life saving in treating cannabis induced psychotic disorder and cannabis withdrawal symptoms. ECT use in these psychiatric disorders has not been reported in the past. Therefore a systematic prospective trial of ECT in cannabis psychosis and craving should be published, and this study is a substantial addition to the literature.

\section{Conclusion}

ECT could be a suitable option in the management of cannabis induced psychotic disorders. This study illuminates that ECT is very helpful and even life saving in the therapy of cannabis psychosis and withdrawal symptoms as well. Although our work clarifies that ECT is functional and practical in the management of these psychiatric disorders, however, a systematic clinical trial of ECT in these conditions should be carried out.

Acknowledgement: No financial support.

\section{Conflict of Interests: Nil}

\section{References}

1. Ahmadi, J., Kamel, M., Ahmed, M.G., et al. Mental Health of Dubai Medical College Students. (2012) Iran J Psychiatry Behave Sci 6(2): 79-83.

2. Ahmadi, J., Kamel, M., Ahmed, M.G., et al. Dubai Medical College students' scores on the Beck Depression Inventory. (2008) IRCMJ 10(3): 169-172.

3. Pridmore, S., Robinson, J., Ahmadi, J. Suicide for scrutinizers. (2007) Australas Psychiatry 15(3): 247-248.

4. Pridmore, S., Ahmdi, J., Majeed, Z.A. Suicide in Old Norse and Finnish folk stories. (2011) Australas Psychiatry 19(4): 322-324.

5. Pridmore, S., Ahmadi, J., Evenhuis, M. Suicide for scrutinizers. (2006) Australas Psychiatry 14(4): 359-364.

6. Mackay-Smith, M., Ahmadi, J., Pridmore, S. Suicide in Shooting Galleries. (2015) ASEAN Journal of Psychiatry 16 (1): 50-56.

7. Ahmadi, J., Ahmadi, N., Soltani, F., et al. Gender differences in depression scores of Iranian and German medical students. (2014) Iran J Psychiatry Behav Sci 8(4): 70-73.

8. Gill, D., Ahmadi, J., Pridmore, S. Suicide and Gambling on the Public Record. (2014) MJP 2(1): 81-88.

9. Khademalhosseini, Z., Ahmadi, J., Khademalhosseini, M. Prevalence of Smoking, and its Relationship with Depression, and Anxiety in a Sample of Iranian High School Students. (2015) Enliven: Pharmacovigil Drug Saf 1(1): 005.

10. Ahmadi, J. Hashish-Induced Olfactory Hallucination: A Novel Finding. (2015) J Psychiatry 18: 330.

11. Ahmadi, J. Excellent Outcome of Psychosis Induced by Methamphetamine Intoxication after 20 Sessions of Electro Convulsive Therapy. (2015) J Addict Depend 1(2): 1- 2.

12. Ahmadi, J., Ekramzadeh, S., Pridmore, S. Remission of Methamphetamine- Induced Withdrawal Delirium and Craving after Electroconvulsive Therapy. (2015) Iran J Psychiatry Behav Sci 9(4): e1793.

13. Ahmadi, J., Sahraian, A., Dastgheib, S.A., et al. ECT and methamphetamine psychosis. (2015) IJMPS 7(1): 51-53.

14. Ahmadi, J., Pridmore, S., Ekramzadeh, S. Successful Use Of Electro Convulsive Therapy in the Management of Methamphetamine Induced Psychosis with Onset During Intoxication. (2015) J Addict Depend 1(1): 1-3.

15. Ahmadi, J., Sahraian, A., Dastgheib, S.A., et al. Management of Methamphetamine-Induced Psychosis by 8 sessions of ECT. (2015) Sch J App Med Sci 3(3H): 1565-1566.

16. Ahmadi, J. Treatment of cannabis related psychosis with electroconvulsive therapy (ECT): a rapid approach. (2016) J Harmoniz Res Med and Hlth Sci 3(1): 44-45.

17. The National Drug Control Report: 2000: Islamic Republic of Iran. (2001) Drug Control Headquarters, International Relations Office

ISSN no: 2471-061X

E-mail: addiction.depend@ommegaonline.org

Website: www.ommegaonline.org 